\title{
THEORETICAL STUDIES OF BILIPROTEIN CHROMOPHORES AND RELATED BILE PIGMENTS BY MOLECULAR ORBITAL AND RAMACHANDRAN TYPE CALCULATIONS
}

\author{
H. SCHEER* $*$ H. FormaneK* and S. SCHNEIDER $\dagger$ \\ *Institut für Botanik der Universität München, Menzinger Strasse 67, D 8000 München 19 and +Institut \\ für Physikalische Chemie. Technische Universität, München, D 8036 Garching, W. Germany
}

(Received I1 January 1982; accepted 23 April 1982)

\begin{abstract}
Ramachandran calculations have been used to gain insight into steric hindrance in bile pigments related to biliprotein chromophores. The high optical activity of denatured phycocyanin, as compared to phycoerythrin, has been related to the asymmetric substitution at ring A, which shifts the equilibrium towards the P-helical form of the chromophore. Geometric effects on the electronic structures and transitions have then been studied by molecular orbital calculations for several conjugation systems including the chromophores of phycocyanin, phytochrome $P_{r}$, cations, cation radicals and tautomeric forms. For these different chromophores some general trends can be deduced. For instance, for a given change in the gross shape (e.g. either unfolding of the molecule from a cyclic-helical to a fully extended geometry, or upon out-of-plane twists of the pyrrole ring A) of the molecules under study, the predicted absorption spectra all change in a similar way. Nonetheless, there are characteristic distinctions between the different $\pi$-systems, both in the transition energies and the charge distribution, which can be related to their known differences in spectroscopic properties and their reactivity.
\end{abstract}

\section{INTRODUCTION}

Biliproteins are receptor pigments involved in photosynthesis and photomorphogenesis (Gantt, 1980; Rüdiger 1979, 1980; Scheer, 1981). Their linear tetrapyrrolic chromophores are characterized by some unusual properties, as compared to free bile pigments, and also to the respective biliproteins after denaturation. The unusual properties arise from non-covalent interactions of the protein and the chromophores. These interactions are hitherto only partly understood, but conformational factors have been suggested as major causes on the basis of chemical and theoretical evidence (Scheer, 1981).

Theoretical calculations have become a powerful tool in conformation analysis of bile pigments. Molecular orbital (MO) + calculations have been performed for free bile pigments with systematic variations of their assumed molecular geometry (and sometimes charge also), with the aim of correlating UV-vis and CD-spectral features with distinct conformations (Burke et al., 1972; Sugimoto et al., 1976; Falk and Höllbacher, 1978; Chae and Song, 1975; Wagnière and Blauer, 1976; Song et al., 1979; Song and Chae, 1979; Pasternak and Wagnière, 1979). More recently, conformational restrictions have also been investigated by Ramachandran type (Scheer et al., 1979) and forcefield calculation (Falk et al., 1981). Most of these theoretical studies, except for Pasternak and Wag-

$\$$ Abbreviations: APC, allophycocyanin; MO, molecular orbital; PC, phycocyanin; $\mathbf{P}_{r}, \mathbf{P}_{\mathrm{fr}}$, phytochrome in its red and far-red absorbing form, respectively. nière (1979), Song et al. (1979) and Song and Chae (1979), have focused on pigments containing the conjugated system of biliverdin (1) and bilirubin, the two main vertebrate bile pigments.

More recently it has been shown that the structure of plant bile pigments exhibit some particular features distinct from those of the vertebrate bile pigments. Nevertheless, in attempts to explain experimental observations, a reference to the MO-calculations, of biliverdin in particular, has often been made. In the light of the many new experimental results a comparative computation of the various $\pi$-systems related to plant bile pigments, applying the same set of parameters to all of them, seems desirable.

A distinguishing feature of all chromophores in biliproteins is the presence of a hydrogenated ring $\mathrm{A}$. The chromophores $\mathbf{2 a}$ and $\mathbf{2 b}$ of phycocyanin (PC), allophycocyanin (APC) and of phytochrome in its $\mathrm{P}_{\mathrm{r}}$-form are examples of these structures. This particular conjugated system has only once been studied systematically by MO-calculations (Pasternak and Wagniere, 1979). The redox properties of the related pigment 3 have also been investigated (Kumbar and MacColl, 1975). Studies on these particular chromophores, however, can aid in the understanding of the protein-chromophore interactions and reactivities which are crucial to the function of biliproteins.

Complementary to chemical reactivity and spectroscopic studies of this conjugation system (Krauss and Scheer, 1981; Kufer and Scheer, 1979) we have recently started a theoretical approach to the conformational analysis of biliprotein chromophores by 
Ramachandran type calculations (Scheer et al., 1979). This study has now been extended to include interactions between rings that are not directly linked and to MO studies on selected structures to assess the influence of conformational and chemical changes on the absorption spectrum and other parameters governed by the $\pi$-electron system.

\section{METHODS}

Ramachandran calculations. These have used a previously published set of parameters (Scheer et al., 1979). The basic geometry of biliverdin (1) was taken from the X-ray data of Sheldrick (1976). The geometries of phycocyanobilin (3), phycocyanin $\mathbf{2 a}$ and the phytochrome $\mathrm{P}$, chromophore $\mathbf{2 b}$ were derived by means of a combination of various X-ray structural results. Basically, the ring B, C, D-fragment was taken from biliverdin (Sheldrick, 1976). that of ring $\mathrm{A}$ from a succinimide of known stereochemistry similar to ring A (Lotter et al.. 1977). No correction has been made for the 18-ethyl group present in $\mathbf{2 a}$ and $\mathbf{3}$ instead of the 18-vinyl group in $\mathbf{2 b}$, due to similar steric parameters.

Molecular orbital calculations. These were performed in the $\pi$-clectron approximation introduced by Pariser, Parr and Pople ('PPP-approximation'). A set of parameters developed earlier (Dörr et al., 1966) was used without modification. This set has successfully been applied in the past for the various types of planar organic molecules (e.g. Melzig et al.. 1981) and no attempt was made to optimize the agreement between calculated and experimental results by modification of the parameters. For non-planar geometries the resonance integrals were chosen as $\beta(x)=\beta_{0} \cdot \cos x$. with $\alpha$ being the torsional angle of the corresponding bonds. In order to take into account the effect of hypercon-<smiles></smiles>

I: $\mathrm{R}=\mathrm{C}_{2} \mathrm{H}_{3}$

6: $R=\mathrm{C}_{2} \mathrm{H}_{5}$<smiles>[R]C1=C(C)/C(=C/C2=[N+]3CCn4c(c(CCC(=O)O)c(C)c4/C=C4\NC(=O)C(C)C4C(C)SP=C)C=C3C(CCC(=O)O)=C2C)NC1=O</smiles>

2a: $R=\mathrm{C}_{2} \mathrm{H}_{5}$

2b: $R=\mathrm{C}_{2} \mathrm{H}_{3}$

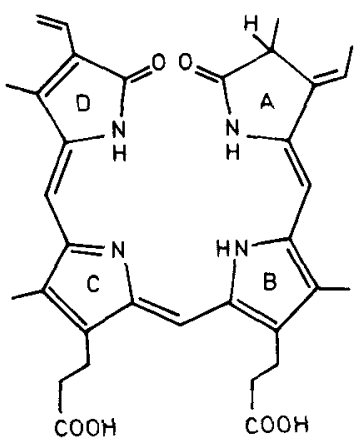

3

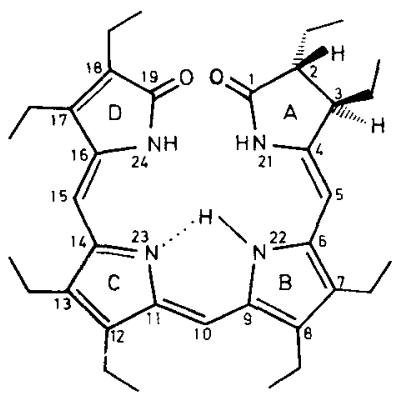

4

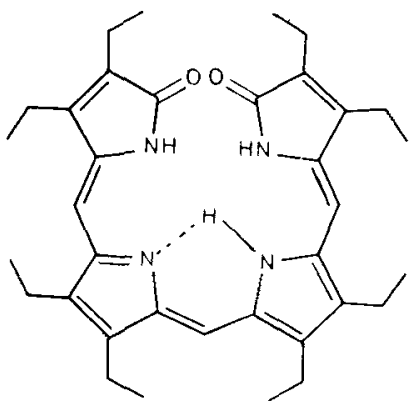

5

Figure 1. Structure and numbering system of investigated bile pigments.

jugation, the carbon atoms numbers 2 and 3 were represented by doubly occupied atomic orbitals with parameters: $\quad U_{x c}=-16 \mathrm{eV} \quad\left(Z^{\circ}=2\right) . \quad \eta_{c c}=10.0 \mathrm{eV}$, $\gamma_{\mathrm{cc}}=5.2 \mathrm{eV}$ and $\beta_{\mathrm{cc}}=0.2 \beta_{0}=-0.48 \mathrm{eV}$.

The values of these parameters are chosen by analogy with the parameters of heteroatoms, which contribute two electrons to the $\pi$-system. Their precise values are not critically important for the resulting excitation energies (e.g. Melzig et al., 1981). The configuration interaction was limited to the 16 lowest singly excited configurations. Test runs including 36 singly excited configurations resulted in essentially the same excitation energies and $f$-values for the first transitions, which are of interest here.

\section{RESULTS AND DISCUSSION}

\section{Ramachandran calculations}

In the previous analysis of $\mathbf{1}$ and $\mathbf{2}$ by Ramachandran calculations, only interactions between rings di- 


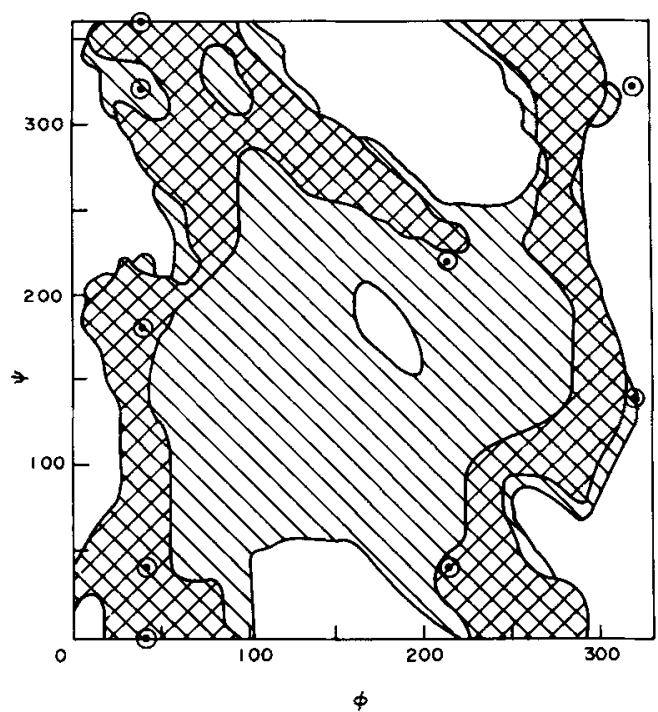

Figure 2. Sterically allowed (cross-hatched areas), possible (lined areas) and forbidden regions (blank) for the A-dihydrobilindion-chromophore of C-phycocyanin and phytochrome $\mathrm{P}_{r}$. The regions correspond to energies in the ranges $\leqslant-1,-1<E \leqslant 0$, and $>0$, respectively. The out-of-plane geometries for the calculations shown in Figs. 7 and 8 are marked $(\odot)$. For the definition of $\phi$ and $\psi$, see footnote below.

rectly linked to each other have been taken into account. In all cyclic geometries of the tetrapyrrole skeleton, an interaction is also expected between the sterically adjacent rings $A$ and $D$. This interaction has been studied by the following approach. The ring B, C, D-fragment has been fixed in the slightly helical geometry present in crystalline 1 . The C-4,5 and the C-5,6-bonds, which are formally a double and a single bond, respectively, have then each been rotated in $10^{\circ}$ increments. The dependence of the total energies on the two angles of rotation, $\phi$ and $\psi^{*}$, as well as the separations of atoms coming critically close to one other, have been summarized in Figs. 2 and 3 . Regions with energy values between 0 and -1 and between -1 and -2 are depicted in Fig. 2 by the lined and cross-hatched areas, respectively.

An important feature of this diagram is its asymmetry. From the two regions of minimum energy which have small positive or negative values of $\phi$, the 'allowed' region for negative twist angles is further from $\phi=0$ than that for positive twist angles. This asymmetry is, of course, due to the asymmetrically substituted C-2 and C-3 present in ring $A$ and sheds further light on the origin of the high optical activity of denatured 2a and $\mathbf{2 b}$ (Lehner et al., 1981; Lehner and Scheer, unpublished). In the denatured pigments,

*The angles $\phi$ and $\psi$ correspond to rotations around the $\mathrm{C}-4,5$ and $\mathrm{C}-5,6$ bond, respectively. These angles have values of $\phi=180^{\circ}$ and $\psi=0^{\circ}$ in the cyclic geometry $\mathrm{A}$. Positive signs are defined for counter-clockwise rotations viewing from $\mathrm{C}-5$. the chromophores are predominantly present in one or more cyclic conformations. Due to the steric hindrance of the $0-1$ and $0-19$ atoms, planar conformations are forbidden and helical conformations are favored. The two possible helices of opposite twist are present in thermal equilibrium (Lehner et al., 1979). Optical activity in bilindions can then arise if either one of the two oppositely twisted, helical forms is present in excess. Such a situation can be induced by dissolution of 1,4 or 5 in chiral solvents (Lehner et al., 1978, 1981), or by the adsorption of 1 to serum albumin (Blauer and Wagnière, 1975; Wagnière and Blauer, 1976). It can also be caused by the presence of asymmetric centers within the molecule (Moscowitz et al., 1964). Earlier Ramachandran calculations (Scheer et al., 1979) taking into account only steric interactions of the asymmetrically substituted ring $A$ with ring $B$ have indicated that $P C$ and $P_{r}$ should exhibit a positive long-wavelength $\mathrm{CD}$ band due to the prevalence of the P-helix (Scheer et al., 1979). This earlier argument, which was based entirely on the interactions between rings $\mathrm{A}$ and $\mathrm{B}$, is now supported by the interactions between rings $A$ and $D$, which again favor the P-helix.

\section{Moiecular orbital calculations}

The conjugated systems studied are summarized in Fig. 5. The 2,3-dihydrobilindion-system (I) is contained in the chromophores of PC and APC (2a), as well as in the model system 4 . In some cases, separate calculations have been performed on its tautomer, II. In addition to the free base I, its protonated form III as well as its cation-radical IV have been considered. The former is already favored below pH 5.25 (Grombein et al., 1975) and may thus be formed within the protein. The latter has been postulated as an intermediate in (photo)oxidation of $\mathbf{4}$ and in the phytochrome photoconversion (Krauss and Scheer, 1979, 1981). For phytochrome $P_{r}$, the 18 -vinyl system $V$ and its tautomer VI have been used (Rüdiger et al., 1981). Since $P C$ and $P_{r}$ perform rather different functions in vivo, the question arises as to the effect of this change of substituents. VII is present in mesobiliverdin (6) and octaethylbilindion (5), VIII is the conjugation system of biliverdin (1). The reactivities of these fully unsaturated pigments differ substantially from those of the dihydrobilindiones (see Scheer, 1981) and it was interesting to check whether these differences could be traced to distinct changes in the $\pi$-system. Finally, the $\pi$-system IX of the 3-ethylidene-bilindion 3 has been included as the main cleavage product of $2 \mathbf{a}$.

The results agree satisfactorily with the known spectral properties of bile pigments. No attempt was made to obtain a better fit by adjusting the basic data set, since many structural details of bile pigments in solution are not yet fully understood and probably more than a single species is present in thermal equilibrium. The focus of this work was rather to investigate the influence of structural variations on the electronic states. These variations have been selected for 


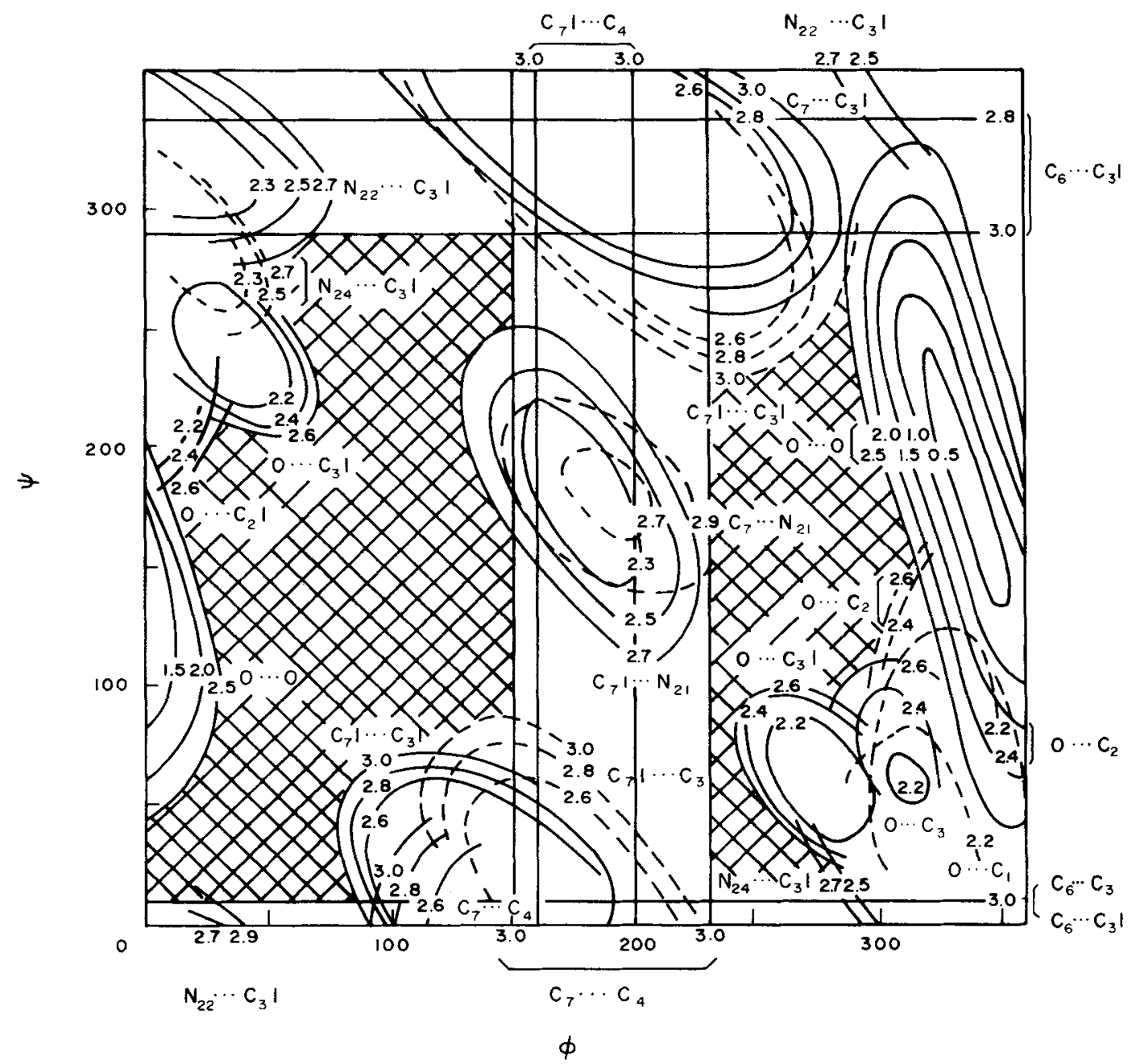

Figure 3. Interatomic distances for non-bonded atoms coming critically close to each other during out-of-plane rotations of ring $\mathrm{A}$ in dihydrobilindions. The axes are given as in Fig. 2 by the torsional angles $\phi$ and $\psi$ of the $\mathrm{C}-4,5$ and $\mathrm{C}-5,6$ bonds, respectively (for definition see footnote to previous page). For each pair of atoms, isodistant profile lines are given in the contact region, with the distance indicated in $[\AA]$.

study on the basis of a suspected or known importance with respect to biliproteins.

\section{Gross shape of the molecules}

To estimate the influence of the gross molecular shape, computations have been made for the basic geometries A. B and C (Fig. 4) with all structures (I-IX) considered. The three basic geometries are the cyclic-helical geometry A (all-syn, Z) $\dagger$, the semi-open $\mathrm{B}$ (anti, Z; syn, Z; syn, Z) and the fully extended C (anti, $\mathrm{Z} ;$ anti, $\mathrm{Z} ; \operatorname{syn}, \mathrm{Z}$ ). The coordinates for the latter

tThe all-sin, $\mathrm{Z}$ geometry $\mathrm{A}$ is similar to that of biliverdindimethylester in the crystal (Sheldrick, 1976), but the twist giving rise to a helical structure has been located at the C-9, 10 and C-10,11 bonds only, rather than on all three methine bridges. two have been derived from the former by rotation around $\mathrm{C}-14,15$ by $180^{\circ}$ and by rotation around $\mathrm{C}-9,10$ and $\mathrm{C}-14,15$ by $180^{\circ}$, respectively.

The changes are most evident in the oscillator strengths of the transitions with excitation energies below approximately $30000 \mathrm{~cm}^{-1}$, corresponding to the absorption bands in the visible and near UV spectral range. Upon opening the cyclic-helical to the more extended geometries, the first transition increases in oscillator strength, whereas the prominent near-UV transitions decrease (Fig. 6). In every case, the change is most pronounced for the first conformational change (rotation around $\mathrm{C}-14,15$ to the semiopen geometry B). This effect is well known theoretically (Burke et al, 1972; Chae and Song, 1975; Sugimoto et al., 1976; Falk and Höllbacher, 1978; Wagniere and Blauer, 1976) and experimentally (Bois- 
<smiles>O=C1CCC(CC2CCC(CC3CCC(CC4CCC(=O)N4)N3)N2)N1</smiles>

A<smiles>O=C1CCC(CC2CCC(CC3CCC(CC4CCC(=O)N4)N3)N2)N1</smiles>

B<smiles>O=C1CCC(CC2CCC(CC3CCC(CC4CCC(=O)N4)N3)N2)N1</smiles>

C

Figure 4. Parent geometries for the MO calculations in Fig. 6. The geometries are indicated in Fig. 6 by the capital letter following the roman number of the respective conjugation system. A corresponds to the cyclic-helical geometry of biliverdin (1a) in the crystal (Sheldrick. 1976), B and $C$ are derived by $180^{\circ}$ rotations at the $C-14,15$ and the $\mathrm{C}-14,15 / \mathrm{C}-10,11$ bonds, respectively.

Choussy and Barbier, 1978; Falk and Thirring, 1981; Lehner et al., 1978) for biliverdin, and has been predicted as well for the A-dihydrobilindion chromophore (Pasternak and Wagnière, 1979; Song and Chae, 1979). The same trend apparently prevails after protonation to the cation (Fig. 6b) and also after oneelectron oxidation to the cation radical (Fig. 6c). The relative intensities of the UV and red bands are thus a good indicator for the gross molecular shape.

By contrast, $\lambda_{\text {max }}$ of the red band strongly depends. for any given geometry, on the length of the conjugated system: a fact which has already successfully been applied as an analytical tool (Köst et al., 1975; Scheer, 1976)

In addition to the red band and a series of more or less closely spaced bands in the near UV, the calculations consistently predict a few bands of medium to small intensity in the intermediate range between $400 \mathrm{~nm}$ and the red band, which are generally most prominent in the semi-open geometry B. The spectra of bile pigments contain generally only two broad, unstructured bands in the spectral region above $300 \mathrm{~nm}$, one in the red to orange and one in the near UV. The existence of transitions with low oscillator strength may explain the non-zero absorption in the region between these bands and the fine structure occasionally seen in the major bands. The existence of these intermediate transitions can be justified on the basis of their importance in the radiationless deactivation of higher excited states, corresponding to the near UV band. Accordingly, in bile pigments fluorescence is observed only from the lowest excited state, whereas in azulene and derivatives for which a similarly wide gap between the absorption bands exists, a dual fluorescence from the first and second excited states is observed. This can be rationalized on the basis of intermediate states of low oscillator strength in the bile pigments, while no such states exist in the azulenes.

In the cation-radical IV, the 'red' absorption band is no longer due to the first but rather the second excited state, with the former giving rise to a band above $1000 \mathrm{~nm}$. The small oscillator strength of the latter, together with its low energy, makes fluorescence of cation radicals unlikely even in the absence of other deexcitation mechanisms. The zinc-complex of a cation radical recently studied is non-fluorescent (Krauss and Scheer, 1979), in contrast to the strong fluorescence of such complexes with closed shell bilindions.

In addition to these common features, some distinct differences between the pigments, especially for IV should be noted:

(i) in the free bases $\mathbf{I}, \mathbf{V}$ and VIII the increase in oscillator strength in the first excitation band is accompanied by a monotonous increase in excitation energy. Whereas this trend also prevails for the extreme geometries $\mathrm{A}$ and $\mathrm{C}$ in III and IV, the semiopen form behaves differently: the protonated III has, in this form, the first transition at highest energy, the cation-radical $\mathbf{I V}$ at lowest energy.

(ii) The near UV region between 300 and $400 \mathrm{~nm}$ is characterized by several transitions. In the cyclic-helical geometry $\mathrm{A}$, it is generally dominated by one strong band, which becomes of comparable intensity to the others in the geometries B and C. Again the cation radical shows a difference. In IV, this region is rather structured with widely spaced bands of comparable intensity in all three geometries.

(iii) In addition to the two major bands ('red' and 'near UV'), there are always transitions in the 'blue' spectral region. These transitions are generally of minor oscillator strength, with a few important exceptions. They are always more pronounced in the semiopen forms and in the cation radical they are expected to be important in either geometry. Free 


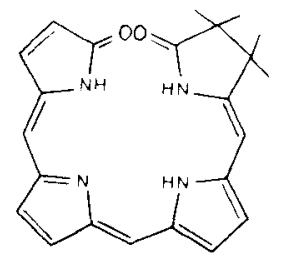

I

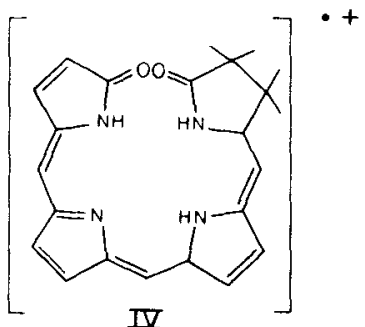

IV

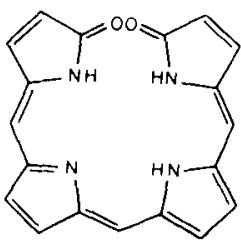

VII<smiles></smiles>

ㅍ<smiles></smiles>

丒

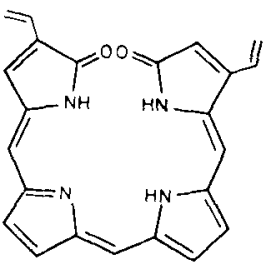

VIII

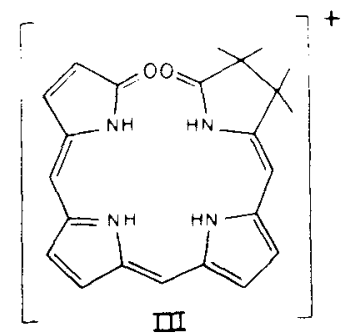<smiles>C=CC1=CC(=Cc2ccc(C=C3C=CC(C=C4NC(=O)C(C)(C)C4=O)=N3)[nH]2)C(C)(C)C1=O</smiles>

VI

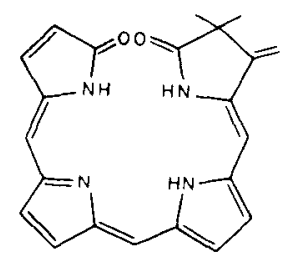

IX

Figure 5. Conjugated systems for the MO calculations presented in their cyclic geometries. They are indicated in Figs, 6-9 by the roman numbers.

cation-radicals of bilindiones have been characterized electrochemically (Eivazi et al., 1977). Their UV-vis spectra are not yet known, but the points (ii) and (iii) are corroborated with respect to IV by the recent observation of a complex band system in the near UV and blue spectral regions for a cation-radical-zinc complex (Krauss and Scheer, 1979).

It also should be noted that rubinoid pigments which can easily be formed from bilindiones by the addition of nucleophiles (including $\mathrm{H}^{-}$-during reduction), absorb (and fluoresce!) in this spectral range (Holzwarth et al., 1978; Kufer and Scheer, 1979). Interestingly, the 'blue' band is absent in phytochromobilin, in which the 18-ethyl group in 3 is replaced by a vinyl substituent.

(iv) The long-wavelength absorption maximum is always shifted to the blue upon unfolding the molecule. This shift is more pronounced for the first step, e.g. cyclic to semi-extended, and in some cases the latter form is even slightly more blue shifted than the fully extended one. This indicates a pronounced interaction of the two 'end-rings', which is already eliminated in the first step of unfolding.

(v) The calculations predict a particularly low intensity of the long-wavelength band in the cyclic form of protonated dihydrobilindion. In 4 (as for bilindions in general), the intensity of this band increases upon protonation (Scheer, 1976), indicating that a more extended conformation is favored for the cations. This could be due to the electrostatic repulsion of the four positively charged nitrogens (see below).

\section{Tautomerism}

The two 'inner' nitrogens $\left(\mathrm{N}_{22}, \mathrm{~N}_{23}\right)$ occupy essentially equivalent positions in the biliverdin-type pigments 1,5 and 6 . The two tautomers with the 'inner' proton at either one of these positions are, therefore, expected to give rise to very similar spectra. This partial symmetry is removed in the dihydrobilindions $\mathbf{2 a}$, b and 4 . The results for the two tautomers I and II bearing the free electron pair at $\mathrm{N}_{23}$ and $\mathrm{N}_{22}$, respectively are shown in Fig. 6a. The ones for the 18-vinylsystem V and VI are similar (not shown). The most pronounced feature is a slight blue-shift of the longwavelength-band, and a shift of the near UV-bands in the opposite direction. The presence of two tautomers thus contributes to the broad appearance of the 


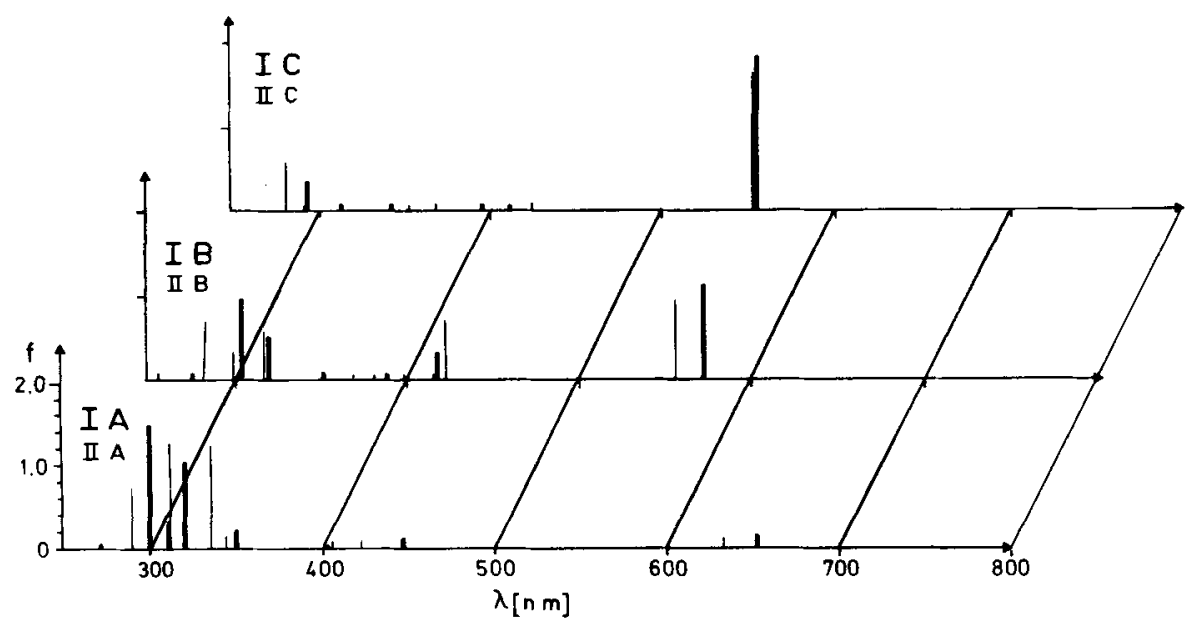

(a)

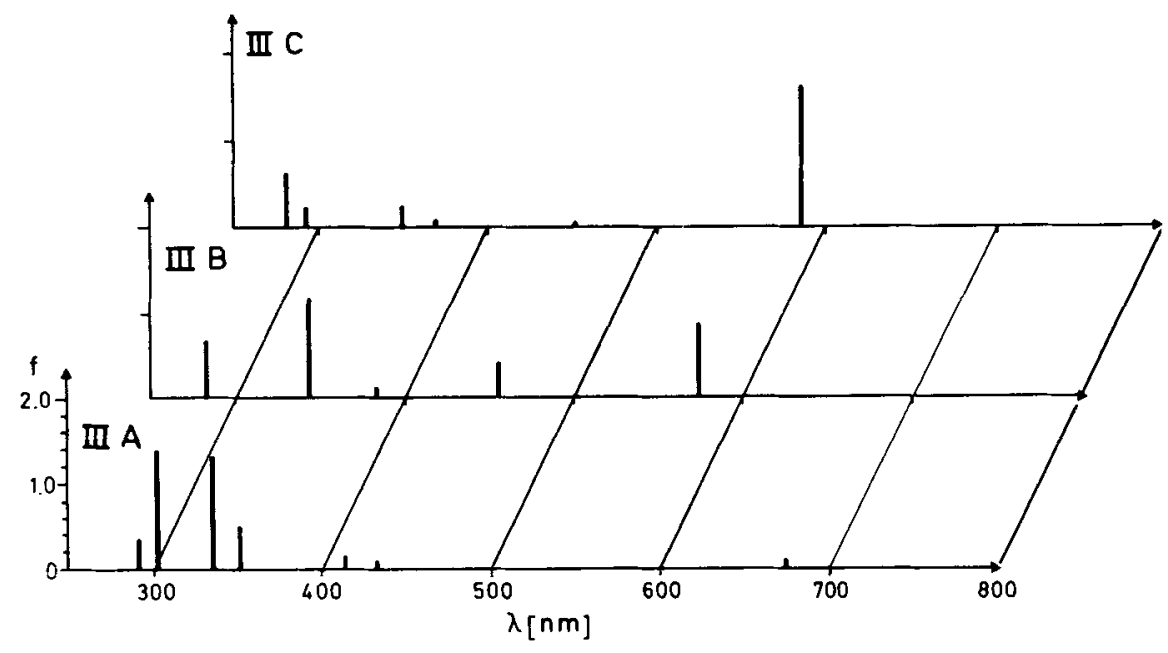

(b)

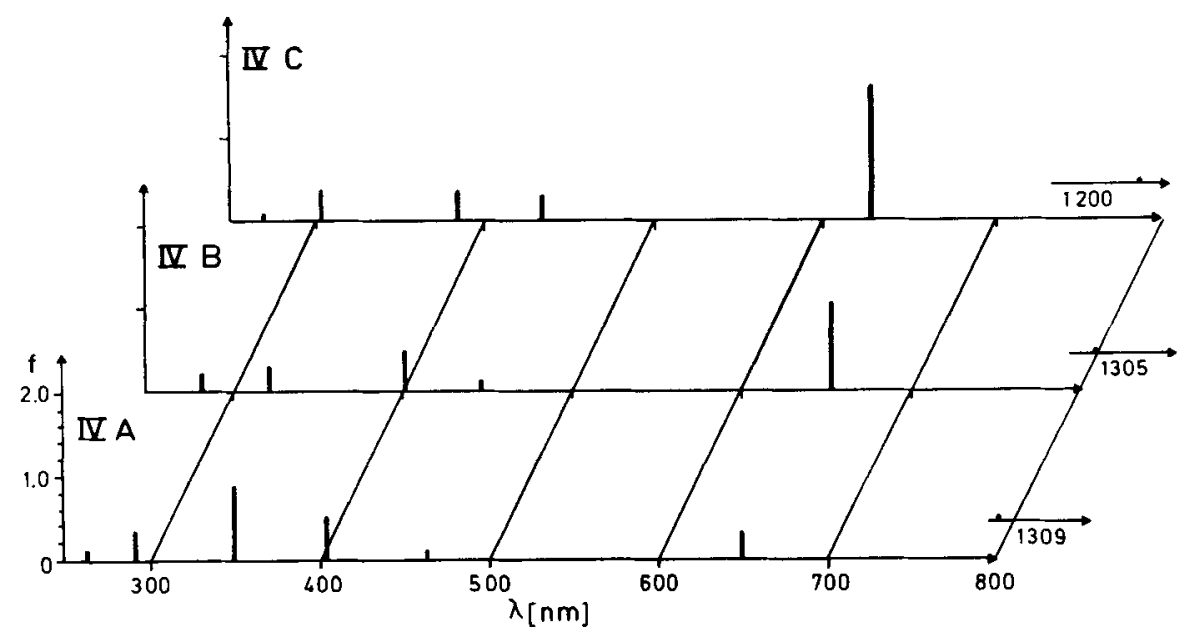

(c) 


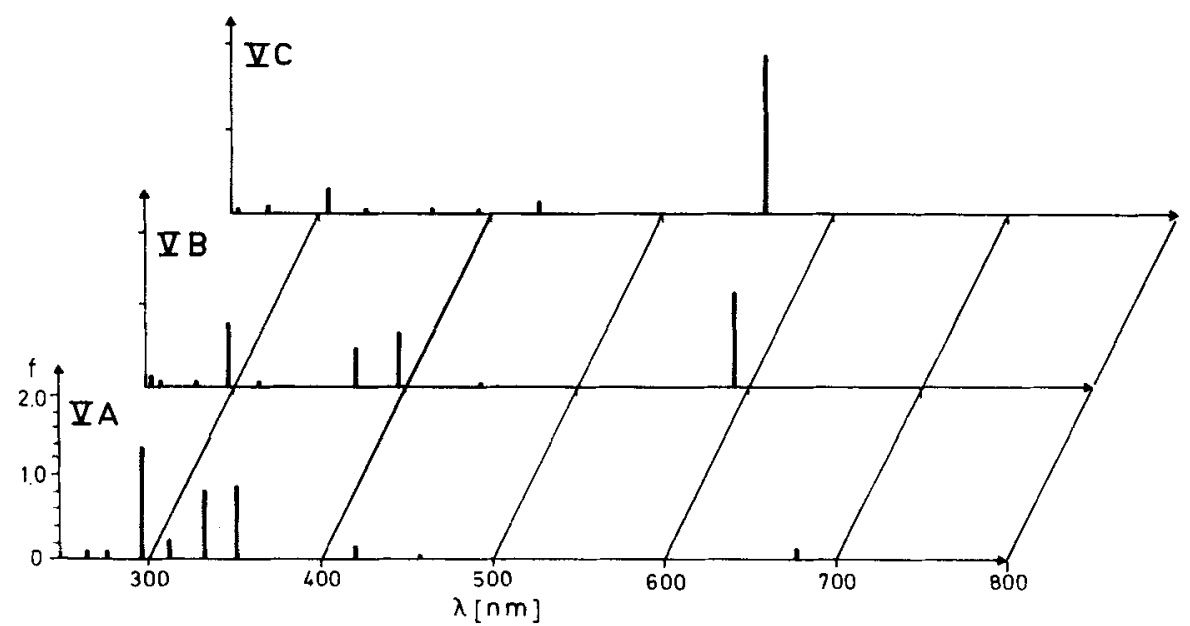

\{d)

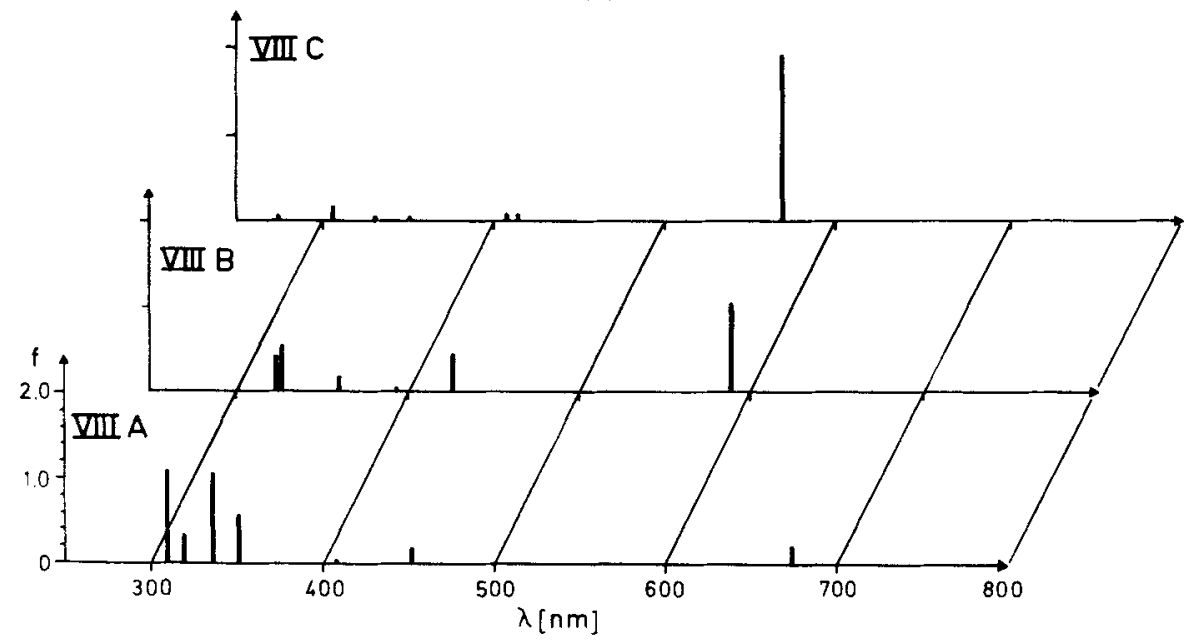

(e)

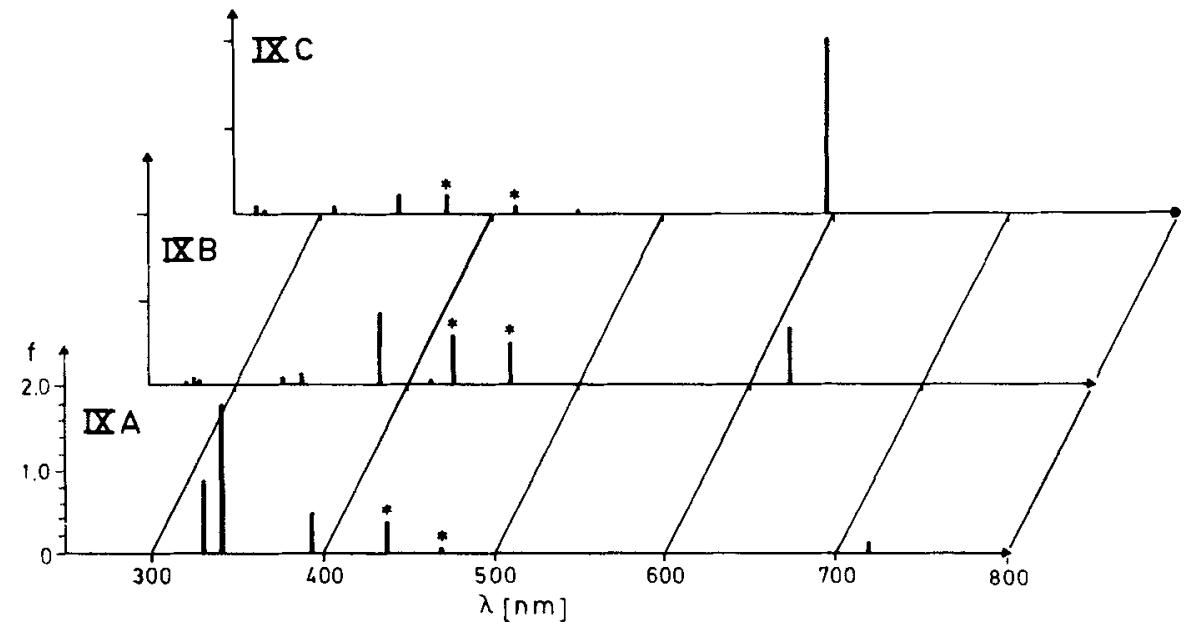

(f)

Figure 6. Shape dependence of bile pigment absorption spectra. Calculated positions $\lambda_{\max }(\mathrm{nm})$ and oscillator strengths of the transitions $<40000 \mathrm{~cm}^{-1}$ of the parent geometries A, B and C (Fig. 4) of the conjugated systems I-V, VII and IX. The respective structures are indicated by the roman number followed by a capital letter in the upper left. In Fig. 6a, the heavy and thin lines correspond to I and its tautomer II, respectively. The transitions marked in (f) with asterisks show charge transfer between vinyl groups and the aromatic system (see 'Influence of vinyl groups'). 
absorption bands. The low temperature photochemistry of bilindions and biliproteins has also tentatively been assigned to a $\mathrm{H}^{+}$-transfer process (Friedrich et al., 1981).

\section{Deviations from planarity}

The results discussed so far have been obtained for bilindiones with almost planar molecular framworks. Here the transitions (but not the topology-dependent electron densities) are strongly influenced by the geometry of the respective $\pi$-systems. The effects of pronounced deviations from planarity have been assessed in I and its tautomer II for selected rotations of $\phi$ and $\psi$ up to $40^{\circ}$ from the respective basic structures $A$ and

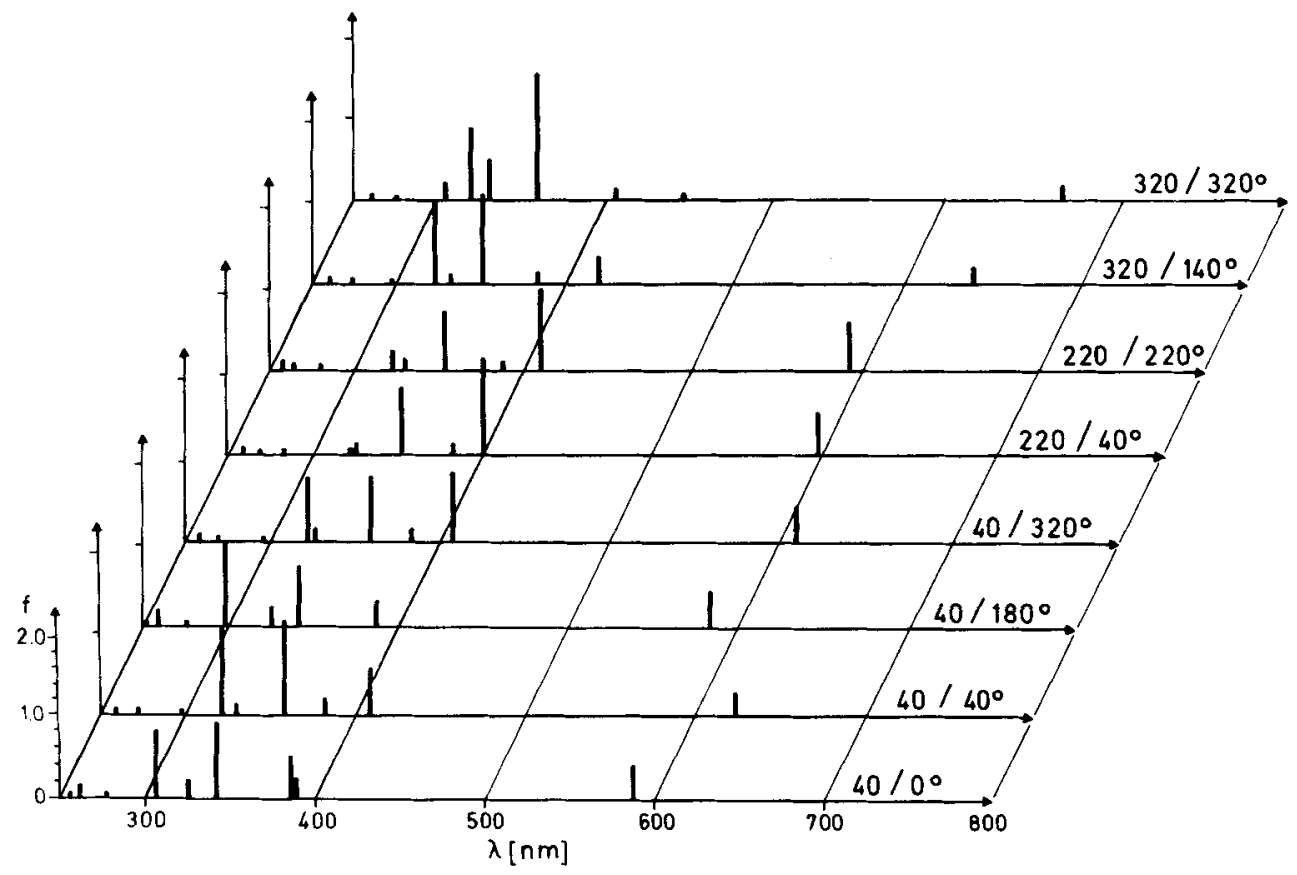

(a)

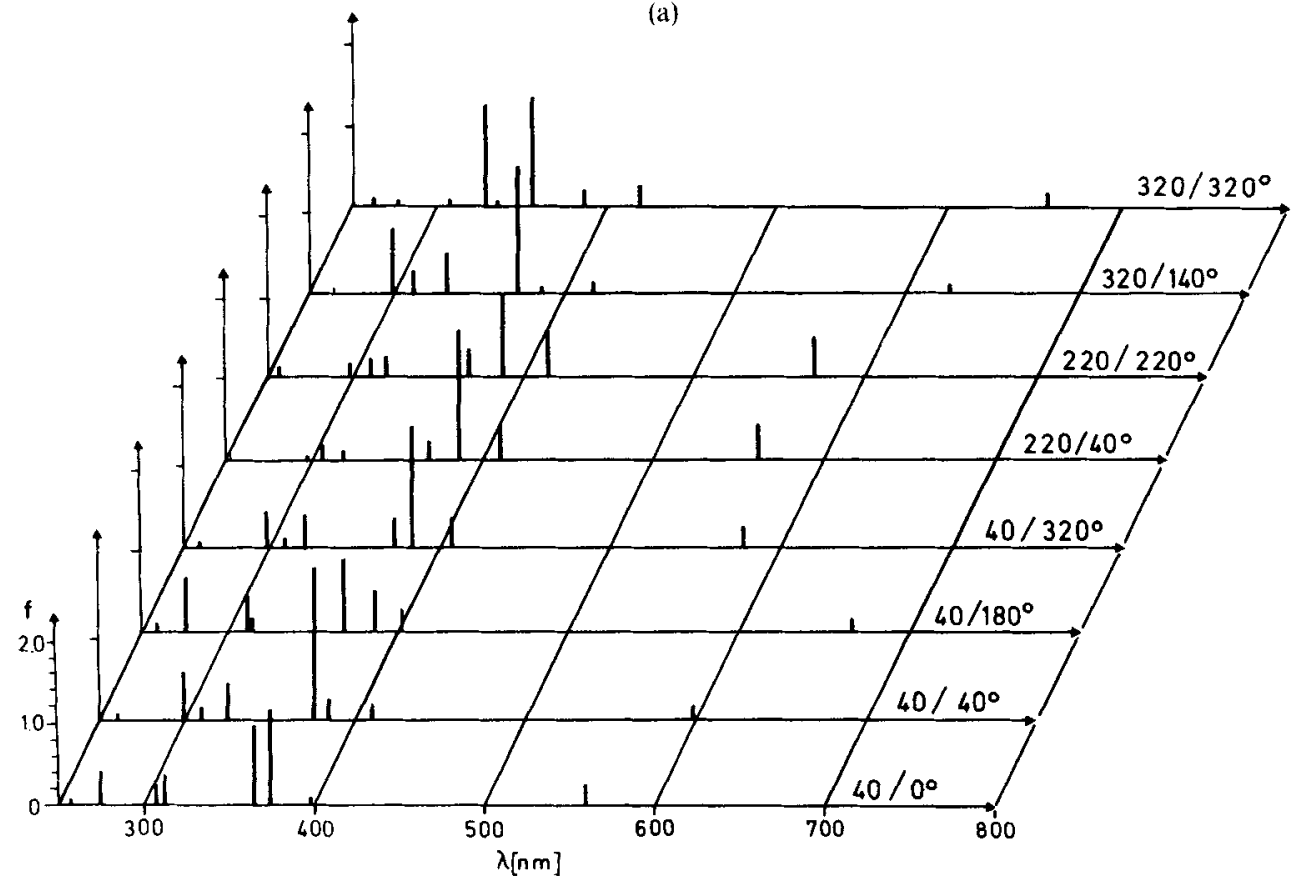

(b)

Figure 7. Deviations from planarity and their effect on the absorption of the A-dihydrobilindion chromophoric system I (7a) and its tautomer II (7b) present in phycocyanins (2a) and the 2,3-dihydrobilindion 4. Calculated positions $(\mathrm{nm})$ and oscillator strengths of the transitions $\geqslant 250 \mathrm{~nm}^{-1}$. The angles are given in the order $\phi, \psi$. The sterically allowed positions defined by $\phi, \psi \leqslant 40^{\circ}$, for which the calculations have been performed, are indicated in Fig. 2 by $\odot$. 
B. It is accepted that rotations of $40^{\circ}$ represent maximum values for which the $\pi$-subsystems are not yet uncoupled. Furthermore, only such geometries which are allowed for steric reasons have been considered (see markings in Fig. 3). The results are summarized in Fig. 7a, b.

For the cyclic forms, a twist of $\phi$ results in a decrease in the ratio of the oscillator strengths $9=\mathrm{f}(\mathrm{UV}) / \mathrm{f}(\mathrm{vis})$ with a concomitant pronounced red- shift of the visible band. Falk et al. (1980) have recently synthesized a 21,24-methanobilindion, which has a distinctly red-shifted band of lower intensity, as compared to the conformationally less restricted bilindions like 1. This spectral characteristic may arise from a larger twist due to the steric effect of the "central' $\mathrm{CH}_{2}$ group, which is indicated from the inspection of molecular models.

In the semi-open conformations, the most character-
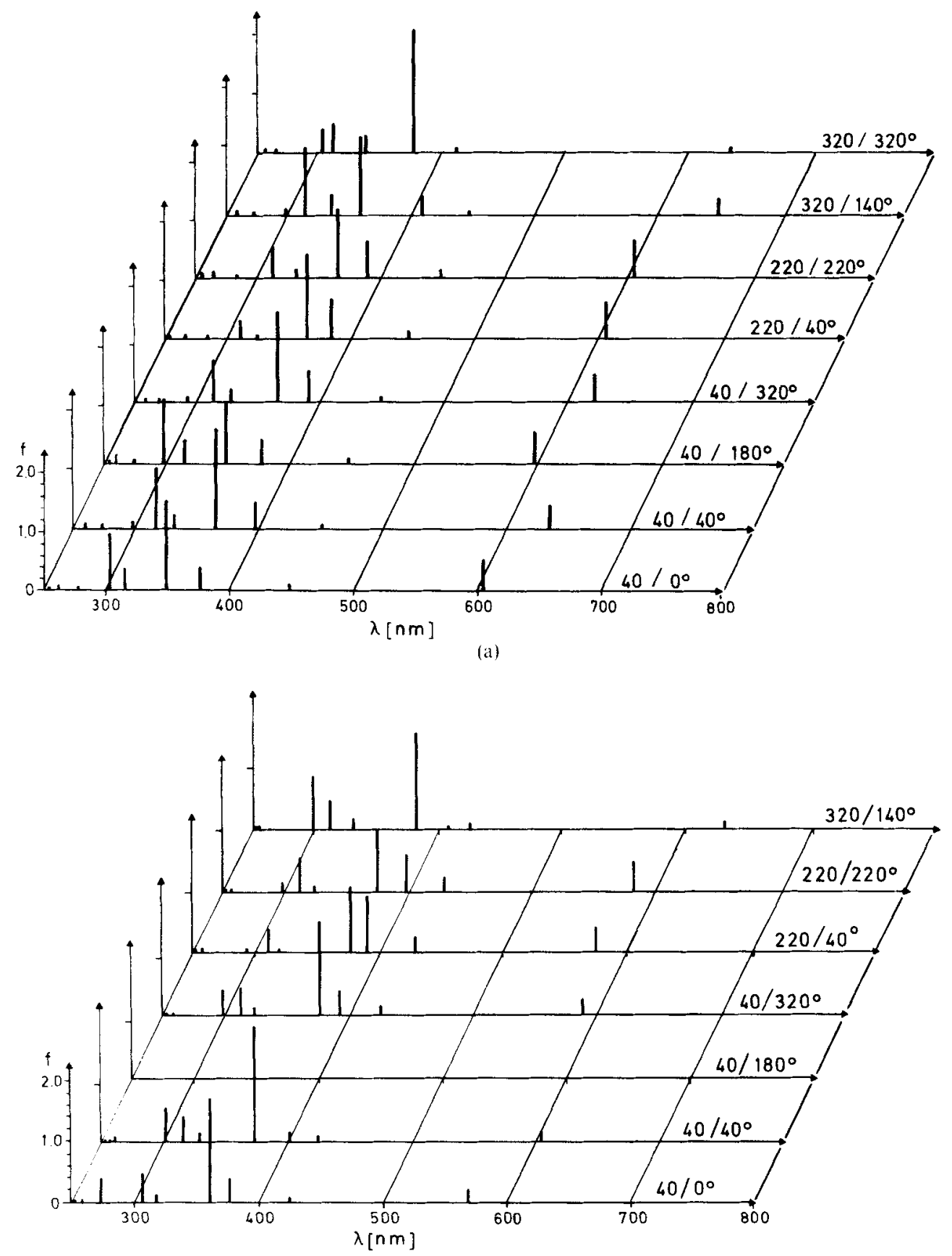

(b)

Figure 8. Deviations from planarity and their effect on the absorptions of the 18-vinyl-2,3-dihydrobilindion chromophoric system $\mathbf{V}(\mathbf{5 a})$ and its tautomer $\mathbf{V I}(\mathbf{5 b})$ present in phytochrome $\mathbf{P}_{1}(\mathbf{2 b})$. Details as in

Fig. 7. 

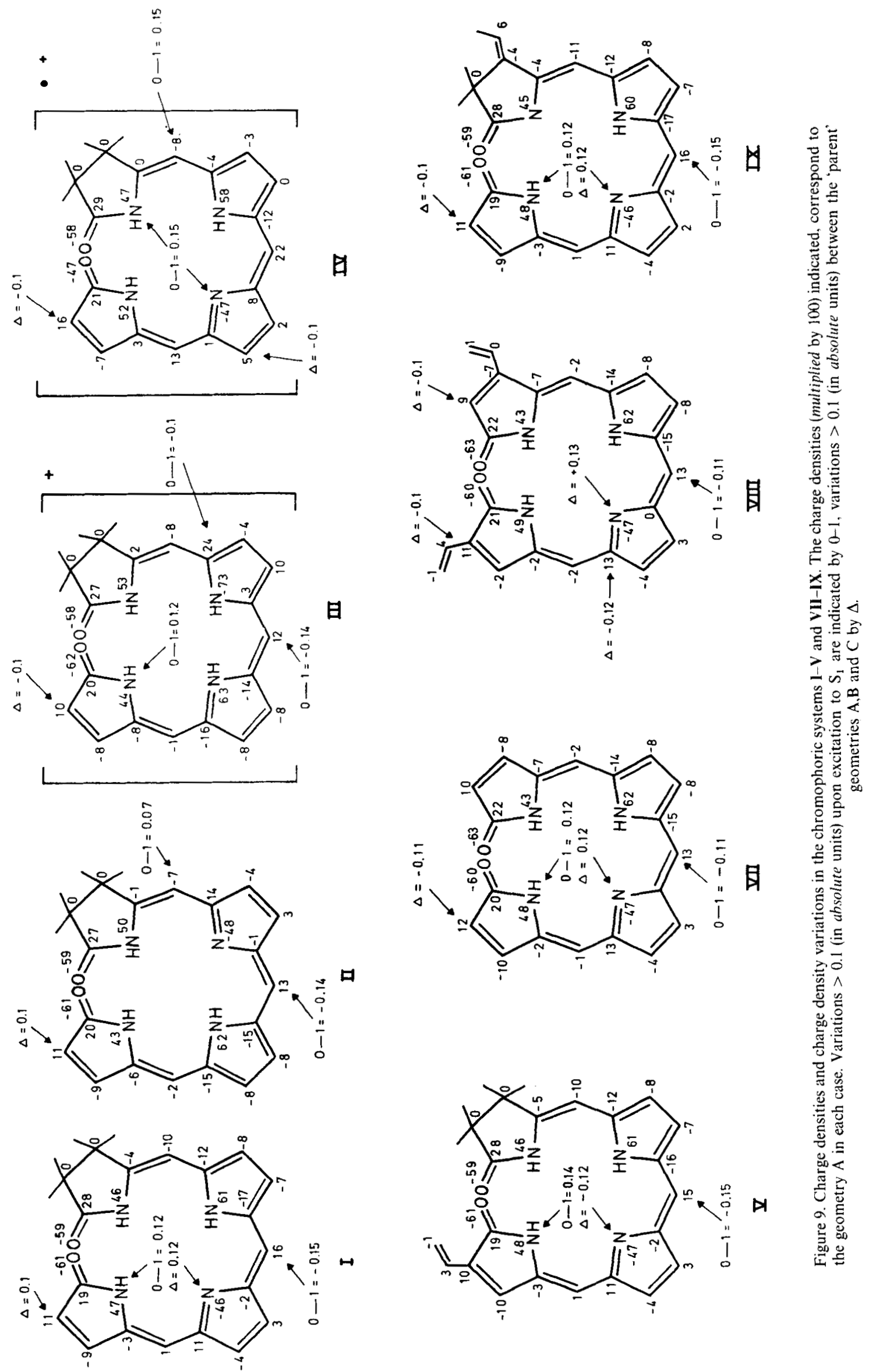
istic feature is an increase in the intensity of the 'blue' band beyond that found for the planar form. Conformations of this type are expected to exhibit a rather unusual spectrum with three bands of similar intensities. The effects of a positive and a negative twist are similar in this respect.

The effect of deviations from planarity has also been studied for the 18-vinylbilindion tautomers $\mathbf{V}$ and VI (Fig. 8). While the trends are similar to those discussed above, two particular features should be noted. Firstly, the absence of a strong third band in the $450 \mathrm{~nm}$ range and secondly, a smail red-shift of approximately $15 \mathrm{~nm}$ for the long-wavelength band. The latter observation is consistent with the extended conjugation system.

\section{Electron densities}

Our investigations have focused on two effects. The first concerns changes in electron density upon opening the cyclic geometry A via the semi-extended form $\mathbf{B}$ to the fully extended geometry $\mathrm{C}$ discussed under the gross shape of the molecule. Figure 9 depicts the $\pi$-electron density of the ground states of geometry A. Only those positions in which the geometry dependent changes $(\mathrm{A} \rightarrow \mathrm{B} \rightarrow \mathrm{C})$ of the net charges, $\Delta$, exceed 0.1 atomic units, have been marked. The second effect concerns changes in net charge upon excitation. Since higher excited states relax rapidly to $S_{1}$ (see above), the most important photophysical and photochemical processes of the bile pigments start from this state. Changes in net charge between $S_{1}$ and $S_{0}$ exceeding 0.1 atomic units are also depicted in Fig. 9 by the symbol ' $0 \rightarrow 1$ '. The next higher singlet states generally do not show any significant new aspects, with the exception of $\mathrm{N}_{24}$ and vinyl substituents discussed below.

The gross molecular shape is generally of only minor importance to the electron density, but the influence is somewhat more pronounced in the fully unsaturated VII and VIII (increase at C-2 and C-18, decrease at $\mathrm{N}$-23) than in the 2,3-dihydro structures $\mathbf{I}$, II, $\mathbf{V}$ and VI.

Excitation to $S_{1}$ produces significant electron density changes at only a few positions. One particular exceptions is $\mathrm{C}-10$. Its low electron density has already been noticed in an earlier MO study of bilindiones (Pullman and Perault, 1959), and the resulting reactivity of this position towards selective nucleophilic attack has since been amply demonstrated (Braslavsky et al., 1978; Kufer and Scheer, 1979; Manitto and Monti, 1979; Falk et al., 1980). This reactivity should decrease upon excitation, because the net charge at $\mathrm{C}-10$ is generally reduced to zero in the $S_{1}$ state. This agrees with our experimental observation of the absence of addition products at C-10 during photochemical studies of I, II and VI (see Scheer, 1981). The changes at other C-atoms are comparably small, with the notable exception of C-5 in the cationradical $\mathbf{I V}$, which shows a pronounced decrease in electron density upon excitation. This may be linked with the selective attack at C-5 during photooxidative reactions of 2,3-dihydrobilindions, which have been suggested to proceed via a cation-radical intermediate (Krauss and Scheer, 1979, 1981). The observed reactions can generally occur in the dark, but are lightassisted, which can be rationalized on the basis of dark formation of the cation-radical and a subsequent photochemical reaction.

Upon electronic excitation pronounced electron density changes at nitrogen atoms occur only for the 'outer' N-21 and N-24, while the 'inner' $\mathrm{N}-22$ and $\mathrm{N}-23$ are less affected. This is the case irrespective of their state of protonation (see Table 1). These changes are more pronounced in the 2,3-dihydrobilindiones I, II, than in the fully unsaturated VI. Proton transfer has been suggested as a deexcitation pathway in bile pigments (Falk and Neufingerl, 1979), as well as a primary photochemical step in the phytochrome interconversion (Song et al., 1981) and photochemical hole burning (Friedrich et al., 1981). According to the results represented in Table 1 , intramolecular proton transfer is expected to proceed between rings $D$ and $C$ in I (or A and B in II), rather than 'inner' rings ( $B$ to $\mathrm{C}$ or vice versa). Furthermore, intermolecular $\mathrm{H}^{+}$-transfer most likely involves $\mathrm{N}-24$. This change in electron density at $\mathrm{N}-24$ is even more pronounced in the $\mathrm{S}_{2}$ and some higher excited states. The more symmetric, fully unsaturated structure VII and IX show a decrease of 0.19 and 0.15 , respectively, while the structures with hydrogenated rings show values up to 0.35 . The only exception to this is the cation-radical IV (0.04). For intramolecular $\mathrm{H}^{+}$-transfer, the difference of the charge density changes at the donor and acceptor atoms is important, rather than the absolute

Table 1. Differences of the net charge changes ( $\Delta \mathrm{e}$, in atomic units multiplied by 100) induced by excitation to $S_{1}$ at the nitrogen atoms bearing protons and the unpaired electron, respectively. Negative sign denotes differences unfavorable for proton transfer (see Fig. 5 for the conjugation systems and Fig. 1, formula 4 for numbering of N-atoms)

\begin{tabular}{lccc}
\hline & \multicolumn{3}{c}{$\Delta$ e between : } \\
\cline { 2 - 4 } systems & $\mathrm{N}_{21}, \mathrm{~N}_{23}$ & $\mathrm{~N}_{22}, \mathrm{~N}_{23}$ & $\mathrm{~N}_{24}, \mathrm{~N}_{23}$ \\
\hline I & 9 & 0 & 17 \\
II & $10^{*}$ & $-4^{*}$ & $9^{*}$ \\
IIIt & 9 & -4 & 8 to 14 \\
IV & 15 to $28 \dagger$ & 4 & 0 to $-5 s$ \\
V & 8 & 2 & 11 to $19 \$$ \\
VII & 8 & 3 & 14 \\
VIII & 9 & -1 & 16 \\
IX & 10 & -5 & 10 \\
\hline
\end{tabular}

*In the tautomeric form II, $\mathrm{N}_{22}$ and $\mathrm{N}_{23}$ have to be interchanged and the headings then read: $N_{21}, N_{22} ; N_{23}$, $\mathrm{N}_{22}$ and $\mathrm{N}_{24}, \mathrm{~N}_{22}$

†Larger for extended conformations, main contribution from $\mathrm{N}_{21}$.

$¥$ Values listed for comparison. In III. only intramolecular proton exchange rather than transfer is possible.

$\$$ Larger for extended conformations, main contribution from $\mathrm{N}_{24}$. 
Table 2. Influence of out-of-plane twists of ring $A$ on the absorption spectra of dihydrobilindions. The twist is indicated by the torsional angles $\phi$ and $\psi$ around the C-4,5 and the C-5,6 bonds, respectively. The geometries investigated are marked by $\odot$ in the Ramachandran diagram (Fig. 2). Excitation energies to the four lowest excited states are given by the corresponding absorption wavelength $\lambda_{\text {m.:x }}(\mathrm{nm})$ and the oscillator strength $\mathrm{f}$. For $\mathrm{S}_{3}$ and $S_{4}$, the angle $\alpha$ (in the quadrant between 0 and $90^{\circ}$ ) between the transition dipoles of the $S_{0} \rightarrow S_{1}$ and the $S_{0} \rightarrow S_{3}, S_{4}$ excitations are given in the last two columns. These transitions correspond to the 'red' and the 'near UV' absorption bands.

\begin{tabular}{|c|c|c|c|c|c|c|c|}
\hline \multicolumn{2}{|c|}{ Twist angle } & \multirow{2}{*}{$i_{\max }^{S_{1}}(\mathbf{n})$} & \multirow{2}{*}{$\lambda_{\max }^{S_{2}}(\mathrm{f})$} & \multirow{2}{*}{$i_{\text {max }}^{S_{3}}(f)$} & \multirow{2}{*}{$\lambda_{\max }^{\mathrm{S}_{\mathbf{4}}}(\mathrm{f})$} & \multicolumn{2}{|c|}{$\begin{array}{l}\text { Transition dipole } \\
\text { angle } \alpha \text { between : }\end{array}$} \\
\hline$\phi$ & $\psi$ & & & & & $\mathrm{S}_{1} / \mathrm{S}_{3}$ & $\mathrm{~S}_{1} / \mathrm{S}_{4}$ \\
\hline \multirow[t]{4}{*}{40} & 0 & $602(0.47)$ & $450(0.05)$ & $378(0.39)$ & $349(1.41)$ & 63 & 68.7 \\
\hline & 40 & $635(0.33)$ & $452(0.03)$ & $398(0.40)$ & $363(1.67)$ & 61 & 61.6 \\
\hline & 180 & $598(0.50)$ & $452(0.04)$ & $382(0.39)$ & $350(0.97)$ & 55 & 62 \\
\hline & 320 & $621(0.43)$ & $452(0.06)$ & $390(0.52)$ & $366(1.47)$ & 56 & 68 \\
\hline \multirow[t]{2}{*}{220} & 40 & $607(0.62)$ & $451(0.15)$ & $385(0.71)$ & $364(1.43)$ & 90 & 95 \\
\hline & 220 & $604(0.64)$ & $452(0.14)$ & $391(0.67)$ & $364(1.10)$ & 75 & 84 \\
\hline 320 & 140 & $651(0.29)$ & $448(0.04)$ & $411(0.34)$ & $361(1.32)$ & 51 & 57 \\
\hline
\end{tabular}

changes themselves. In the case of some indigoids and anils, which exhibit a comparatively high degree of conformational and tautomeric freedom, MO calculations with the same basic set have also predicted such differences of charge density changes around 0.15 for atoms involved in $\mathrm{H}$-bonding. It has been shown experimentally that this is sufficient to make proton transfer an efficient deexcitation pathway (Melzig, 1981). The changes in bile pigments are less pronounced (Table 1). The rapid radiationless decay of $S_{1}$ in free bile pigments may then require other (additional) mechanisms, e.g. the flexibility of these molecules.

\section{Influence of vinyl groups}

Other electron density changes $\geqslant 0.1$ are only observed in the vinyl-substituted pigments $\mathbf{V}$ and $\mathbf{V I}$ and VIII. Here, some of the higher excited states (marked with asterisks in Fig. 6f) show a prominent charge transfer between the vinyl group(s) and the aromatic system.

In the ground and the first excited state(s) the vinylgroups are only loosely coupled to the tetrapyrrole system. The transition to the $\mathrm{S}_{1}$-state, therefore, represents the 'localized' excitation of the tetrapyrrole conjugation system. Since the excitation of isolated double bonds requires far UV light, the vinyl groups affect neither the excitation energy nor the charge distribution and the oscillator strengths in a pronounced way. Experimentally, vinyl groups in bilindions produce only a slight red shift in both the near UV and the red band, with the extinction coefficients and their ratios being dependent on the 'endo' ( $\mathrm{C}-3$ or $\mathrm{C}-17$ ) or 'exo' position (C-2 or C-18) (Stoll and Gray, 1977). The electron density at $\mathrm{C}-10$, and thus the reactivity towards nucleophiles, remains unchanged by the vinyl groups.

\section{Tautomerization}

Tautomerization (I vs. II) leads to an inverted electron density map of rings $\mathrm{B}$ and $\mathrm{C}$, with rings $\mathrm{A}$ and
$\mathrm{D}$ being essentially unaffected. In the protonated form III, formally derived from tautomer I, the electron densities of rings $\mathrm{A}, \mathrm{B}$ and $\mathrm{D}$ remain unchanged, whereas that of ring $C$ becomes similar to that of the corresponding ring in the tautomer II. Apparently, the state of protonation affects only the rings directly involved. Such localized effects have also been observed in other areas of bile pigment research, e.g. in proton NMR (Kraus, 1980).

\section{Orientation of transition dipole moments}

Transition dipole moments of the 'planar' geometries have small to negligible Z-components. They increase, as expected, in going to non-planar conformations. Although the relative contributions of $\mathrm{D}_{x}$, $\mathrm{D}_{y}$ and $\mathrm{D}_{z}$ to the total transition dipoles change considerably, the angles between them remain fairly constant (Table 2). Since fluorescence depolarization and linear dichroism experiments generally yield only the relative orientations of these dipoles, their interpretation with respect to molecular geometry is thus ambiguous. It also appears that the $\mathrm{Q}$-values only poorly refiect the geometric changes from planar to nonplanar conformation. The ratio of oscillator strengths of the first transition to that of the summed near UV-transitions $\left(S_{3}, S_{4}\right)$ remains roughly constant (Table 2).

Acknowledgements-We thank the Deutsche Forschungsgemeinschaft for financial support. We are indebted to Dr. $\mathrm{G}$. Woolfe for linguistic assistance in the preparations of this manuscript.

\section{REFERENCES}

Blauer, G. and G. Wagnière (1975) J. Am. Chem. Soc. 97, 1949-1954

Bois-Choussy, M. and M. Barbier (1978) Heterocycles 9, 677-690.

Brandlmeier, T., H. Lehner and W. Rüdiger (1981) Photochem. Photobiol. 34, 69-73.

Burke, M. J., D. C. Pratt and A. Moscowitz (1972) Biochemistry 11, 4025-4031. 
Chae, Q. and P.-S. Song (1975) J. Am. Chem. Soc. 97, Lehner, H., C. Krauss and H. Scheer (1981) Z. Natur$4176-4179$. forsch. 36b, 735-738.

Dörr, F. G. Hohlneicher and S. Schneider (1966) Ber. Lotter, H., G. Klein, W. Rüdiger and H. Scheer (1977) Bunsenges. Phys. Chem. 70, 803-807. Tetrahedron Lett. 2317-2320.

Eber, G., F. Grüneis, S. Schneider and F. Manitto, P. and D. Monti (1979) Experientia 35, Dörr (1974) Chem. Phys. Lett. 29, 397-404.

Eivazi, F., W. M. Lewis and K. M. Smith (1977) Tetrahedron Lett. 3083-3086.

Falk, H. and G. Höllbacher (1978) Monatsh. Chem. 109, $1429-1449$.

Falk, H., G. Höllbacher, O. Hofer and Müller (1981) Monatsh. Chem. 112, 391-403.

Falk, H.. N. Müller and T. Schlederer (1980) Monatsh. Chem. 111, 159-175.

Falk, H. and F. Neufingerl (1979) Monatsh. Chem. 110, 987-1001

Falk, $H$ and K. Thirring (1981) Tetrahedron 37, 761766.

Frjedrich, J., H. Scheer, B. Zickendraht-Wendelstadt and D. Haarer (1981) J. Am. Chem. Soc. 103, 1030-1035.

Gantt, E. (1980) Int. Rev. Cytol. 66, 45-80.

Grombein, S., W. Rüdiger and H. Zimmermann (1975) Hoppe Seyler's Z. Physiol. Chem. 356. 1709-1714.

Holzwarth, A. R., H. Lehner, S. E. Braslavsky and K. Schaffner (1978) Liebigs Ann. Chem. 2002-2017

Köst, H.-P., W. Rüdiger and D. J. Chapman (1975) Liehigs Ann. Chem. 1582-1593.

Krauss, C. (1980) Dissertation, Universität München.

Krauss, C. and H. Scheer (1979) Tetrahedron Lett. 3553--3556.

Krauss, C. and H. Scheer (1981) Photochem. Photobiol. 34, 385-391

Kufer, W. and H. Scheer (1979) Hoppe-Seyler's Z. Physiol Chem. 360, 935-956.

Kumbar, M. and R. MacColl (1975) Res. Commun. Chem. Pathol. Pharmacol, 11, 627-637.

Lehner, H., S. E. Braslavsky and K. Schaffner (1978) Liebigs. Ann. Chem. 1990-2001.

Lehner, H., W. Riemer and K. Schaffner (1979) Liebias Ann. Chem. 1798-1801. 1418-1420.

Melzig, M. (1981) Dissertation, Technische Universität München.

Melzig, M., S. Schneider, F. Dörr and E. Dalbrozzo (1980) Ber. Bunsenges. Phys. Chem. 84, 1108-1114.

Moskowitz, A., W. C. Krueger, I. T. Kay, G. Skews and S. Bruckenstein (1964) Proc. Natl. Acad. Sci. USA 52, 1190-1194.

Pasternak, R. and G. Wagnière (1979) J. Am. Chem. Soc. 101, 1662-1667.

Pullman, B. and A.-M. Perault (1959) Proc. Natl. Acad Sci. USA 45, 1476-1480.

Rüdiger, W. (1979) Ber. Dtsch. Bot. Ges, 92, 413-426

Rüdiger, W. (1980) Struct. Bonding 40, 101-140.

Rüdiger, W!, T. Brandlmeier, I. Blos, A. Gossauer and J.-P. Weller (1980) Z. Naturforsch. 35c, 763-769.

Scheer, H. (1981) Angew. Chem. 93, 230-250; Angew. Chem. Int. Ed. Engl. 20, 241-261.

Scheer, H., H. Formanek and W. Rüdiger (1979) $Z$. Naturforsch. 34c, 1085-1093.

Sheldrick, W. S. (1976) J. Chem. Soc. Perkin Trans. ? 1457-1462.

Song, P.-S. and Q. Chae (1979) Photochem. Photobiol. 30, $117-123$.

Song, P.-S., Q. Chae and J. D. Gardner (1979) Biochim. Biophys. Acta 576, 479-495.

Song, P. S., H. K. Sarkar, I. S. Kim and K. L. Poff (1981) Photochem. Photobiol. 27, 369-382.

Stoll, M. S. and C. H. Gray (1977) Biochem. J. 163 , 59-101.

Sugimoto, T., M. Oishi and H. Suzuki (1976) J. Phys. Soc. Jpn. 43, 619-626.

Wagnière, G. and G. Blauer (1976) J. Am. Chem. Soc. 98, 7806-7810 